\title{
MATRIX METHOD OF COMPETITIVE ANALYSIS OF THE RESULTS OF ECONOMIC ACTIVITY OF HOSPITALITY ENTERPRISES IN THE CONDITIONS OF STRATEGIZATION AND DIGITAL TRANSFORMATION
}

\author{
Garafonova Olha', Zhosan Hanna ${ }^{2}$, Marhasova Viktoriia ${ }^{3}$, Tkalenko Nataliia ${ }^{4}$, \\ Trukhachova Kateryna ${ }^{5}$
}

${ }^{1}$ Doctor of Economics, State Higher Educational Institution, Kyiv National Economical University named after Vadym Hetman, Victory Avenue, 54/1, Kyiv, Ukraine, Email: ogarafonova@ukr.net

${ }^{2} \mathrm{PhD}$, Kherson State Agrarian and Economic University, street Stretenskaya 23, Kherson, Ukraine, Email: enn89@ukr.net

\begin{abstract}
${ }^{3}$ Doctor of Economics, Chernihiv Polytechnic National University, street Shevchenko, 95, Chernihiv, Ukraine, Email: viktoriya.margasova@gmail.com

${ }^{4}$ Doctor of Economics, Chernihiv Polytechnic National University, street Shevchenko, 95, Chernihiv, Ukraine, Email: tnv2504@gmail.com
\end{abstract}

${ }^{5}$ PhD, Kherson National Technical University, Berislavske Shosse, 24, Kherson, Ukraine, Email: veratrinacholi@ ukr.net

Received 1903 2021; Accepted 13042021

\begin{abstract}
It is proposed to determine the overall level of economic activity of hospitality enterprises through complex indicators of effectiveness: index of final results of economic activity, index of resource use that express the change in the relative level of economic efficiency for the period under study. The reference value of the indicator of efficiency of economic activity of the enterprise is taken as $100 \%$, as the best result at which economic activity is effective, is at a high level, and the set goals are achieved. On the basis of the obtained data with the help of cluster analysis, the ranges of efficiency of economic activity are allocated and the distribution of hospitality enterprises by efficiency in the distribution matrix for 2016-2019 is made. As a result of the study of economic activity of hospitality enterprises and evaluation of the effectiveness of their economic activity, it is found that in general, for the period 2016-2019 the efficiency of economic activity of hospitality enterprises is determined in relation to low indexes of final results of economic activity and use of resources (both less than one), so it is impossible to make a conclusion about the overall positive picture of enterprises.
\end{abstract}

Key words: results, analysis, economic activity, hospitality enterprises, matrix method.

JEL Classification: $014,031, P 41$.

\section{Introduction}

The enterprise is a socio-economic, production, and commercial system that exists to achieve certain goals through the transformation of resources into products or services aimed at meeting the needs of consumers. The implementation of management measures, as well as the current management of major processes in the enterprise, requires an adequate assessment of its economic activity. Unfortunately, the management of the economic activity of the enterprise is often carried out without taking into account the degree of achievement of goals and resources spent on their achievement. The main task of managing the economic activity of an enterprise operating in modern economic conditions is its productive activity, both in the long run and in the short

Copyright (C) 2021 Author(s), published by Vytautas Magnus University. This is an open access article distributed under the terms of the Creative Commons Attribution Non-Commercial 4.0 (CC BY-NC 4.0) license, which permits unrestricted use, distribution, and reproduction in any medium provided the original author and source are credited. The material cannot be used for commercial purposes. 
term. Thus, efficiency is defined not only through the reception of a certain result for the achievement of the set purposes, but also rational use of the resources of the enterprise directed on the realization of the purposes.

The effectiveness of economic activity of the enterprise is a complex multi-criteria characteristic that complicates the process of its provision. Any inconsistency of economic processes that require certain resources and are assessed by indicators that characterize the individual results of the enterprise, can lead to a loss of competitive position in the market and reduce the success of economic activity. Ensuring the effectiveness of economic activity should be based on the ability of management to overcome internal inconsistencies through the balanced use of enterprise resources and focus on opportunities.

\section{Literature analysis}

A significant contribution to the study of the essence, evaluation and management of effectiveness was made by foreign scientists: E. Dolan, P. Drucker, G. Kokins, D. Sink and scientists of Ukraine and the CIS countries: L. Abalkin, N. Avanesova, A. Borisov, N. Burova, N. Haydamak, I. Gontareva, O. Gonchar, L. Dogadailo, R. Darmits, T. Zagorna, O. Zagorodniy, N. Kizima, V. Kovalenko, V. Kovalev, O. Korintseva, T. Kosyanchuk, O. Kuzmin, L. Ligonenko, L. Lyakhova, L. Melnyk, N. Mykolaychuk, O. Oleksyuk, S. Pokropivny, A. Porshnev, G. Savina, A. Safina, J. Svitlychna, A. Tyshchenko, Yu. Ushkarenko, L. Fedulova, M. Sharko, A. Sheremet, Z. Shershneva, and others.

Thus, Kosyanchuk T. and Galkina Y. emphasize that efficiency and effectiveness are "essentially synonymous terms that characterize the same production processes". They define "efficiency", referring to the interpretations adopted in foreign countries with developed market economies, as a comprehensive reflection of the final results, the use of means of production and labor for a certain period of time. According to them: "efficiency finds a specific quantitative expression in the interconnected system of economic efficiency indicators, characterizing the efficiency of the main elements of the production process" [8, p. 123].

A similar point of view is expressed by Barsov A.: "according to its initial generic feature, efficiency is the essence of effectiveness, i.e., the result of activity (effect) obtained by society or an individual per unit of used (or spent) resources" [1, p.13].

Similar in meaning, definitions that identify the concepts of "effectiveness" and "efficiency" can be found in the works $[2 ; 3$; 12] where "effectiveness" is considered in the sense of "efficiency" and is characterized by the ratio of the obtained effect, the result to the cost of factors, resources, which led to this result. In all of the above definitions, effectiveness is seen as synonymous with efficiency and reflects certain activities aimed at obtaining a result through the use of resources that led to the receipt of this result.

There is another approach in which "effectiveness" is considered as an integral part of "efficiency", but no longer in the sense of "essence", but in the sense of "dependent indicator" or "component". Thus, Sheremet A. and Saifulin R. define effectiveness as a component of efficiency, characterized by the work of the enterprise and the return on its capital, resources or products [158]. Scientists R. Darmits R. and Vatsyk N. define effectiveness as the ability of the management system to create conditions for the realization of goals and stable development of economic efficiency, which, in particular, depends on the extent and number of results achieved by the company for a certain period [7, p. 155].

In the recommendations of the Organization for Economic Cooperation and Development on the evaluation and measurement of effectiveness of the activity, effectiveness is defined as a component of efficiency, the level of goals achieved or the expected level of achievement in the future, taking into account their relative importance. It is also noted that effectiveness is a cumulative measure of the value of an activity or its quality, i.e., to what extent the main goal of the 
activity will be achieved in an effective way with sustainable development. And efficiency itself is defined as a measure of how economically resources / inputs (funds, experience, time, etc.) are converted into results / outputs [18].

Mescon M., Albert M., Hedoury F. give the following definition of "economic efficiency of the enterprise" is the most important measure of effectiveness of enterprises, which is a comparison of the results of these activities. The economic efficiency of the enterprise is the ratio of results to costs. They determine the effectiveness not only as an indicator that depends on efficiency, but also as one that takes into account additional parameters responsibilities, adaptability and development, i.e., characterizes the activities of the enterprise in terms of environmental impact on its development [11, p. 59].

Tishchenko A., Kyzyma N., Dogadailo L. define the effectiveness of the enterprise as a generalizing quantitative phenomenon that arises as a result of effective implementation of activities and combines more specific quantitative phenomena that reflect the final effectiveness of the enterprise [15]. That is, effectiveness, as an indicator of the evaluation of the enterprise, in this perspective can't exist without efficiency and acquires the essence of a kind of "result" of efficiency.
Taking into account the unconditional value and importance of research, in the scientific works of these authors the effectiveness of economic activity of the enterprise studied insufficiently from the standpoint of balance, the specifics of ensuring the effectiveness of economic activity including hospitality did not consider, which determines the relevance of the topic of the work, purpose and objectives of the study in theoretical and practical aspects.

\section{Aims of the article}

The purpose of the article is to analyze the results of economic activity of hospitality enterprises using the matrix method.

\section{Results}

In our opinion, the main tool for assessing the effectiveness of economic activity is the matrix method, as a model of full-system analysis, which provides information about the main results of the enterprise, creates prerequisites for obtaining general information on all effectiveness criteria as a whole and in individual activities.

The model of full-system connection of economic categories and formulas of their definition was first introduced in economic researches of Mereste U. [6; 9; 10].

Copyright (C) 2021 Author(s), published by Vytautas Magnus University. This is an open access article distributed under the terms of the Creative Commons Attribution Non-Commercial 4.0 (CC BY-NC 4.0) license, which permits unrestricted use, distribution, and reproduction in any medium provided the original author and source are credited. The material cannot be used for commercial purposes. 


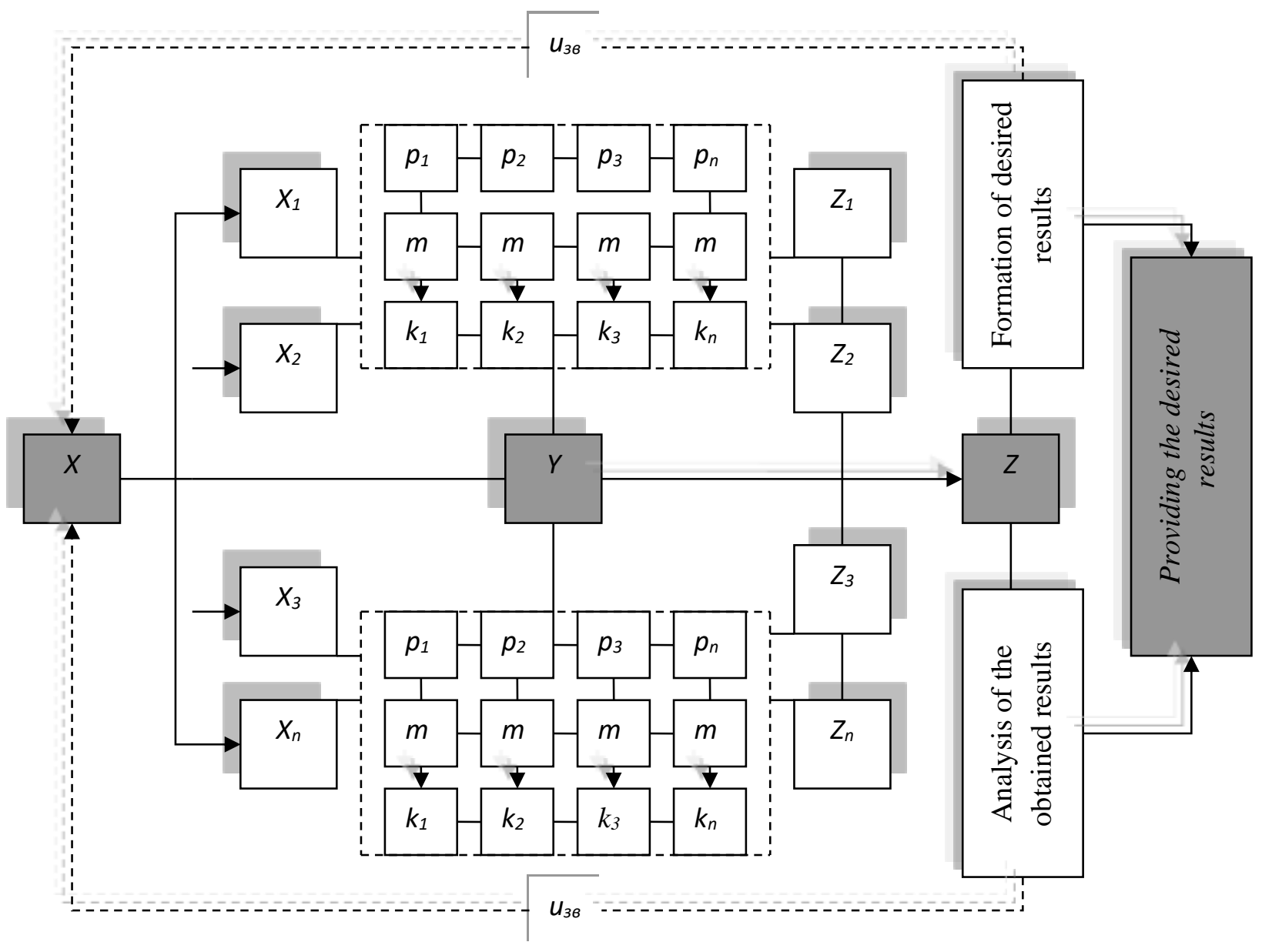

Figure 1. Block diagram of the desired results of economic activity of the enterprise*

(Developed by the authors)

( $X$ - input of the enterprise (resources); $Y$ - the main processes of the enterprise; $Z$ - outputs of the enterprise (results); $p_{n}$ - parameters of economic activity; $m_{n}$-capabilities of the enterprise; $k_{n}$-ratio of parameters and resource capabilities of enterprises (indicators); $u_{f b}$-feedback "coordination" (definition and allocation of resources))

It should be noted that the model of fullsystem analysis is based on a theoretical concept, the main content of which is the use of significant versatility of any economic category in its actual manifestation through a one-sided means of modeling. This approach is considered full-system and divides it into the following stages: construction a full-system model by constructing fields of relations and choosing the indicators that are part of the system; construction on the basis of selected indicators of the matrix model.

The developments of Mereste U. were further developed, and some works differ from the original source in the qualitative and quantitative composition of indicators in matrix form $[4 ; 5 ; 13 ; 14 ; 15 ; 16]$.

Analysis of the effectiveness of economic activity and the general condition of the enterprise contains a large number of indicators. For the purposes of the analysis, it is necessary to use only those indicators which are an information basis for acceptance of administrative decisions.

The following enterprises of Kherson were selected to evaluate the effectiveness of economic activity of hospitality enterprises: Hotel "Angelina", Hotel "Gostiny Dvir", Hotel "Greenstone", Hotel "Muscat", Hotel "Bordo", Hotel "Non-stop". 


\section{S sciendo}

Management Theory and Studies for Rural Business and Infrastructure Development

eISSN 2345-0355. 2021. Vol. 43. No. 2: 237 - 248

Article DOI: https://doi.org/10.15544/mts.2021.20

The selected hospitality enterprises are similar in the set of management parameters, among which are the following: type of enterprise; location in the city; equal competitive positions in the market of hotel services; similarity of the range of services; similar technologies and organization of the service delivery process; similar number of staff; similarity of material and technical base and size; similarity of number fund; the same external environment. To analyze the results, a set of indicators of economic activity of hospitality enterprises for 2016-2019 was determined.

The analysis of the economic situation at the enterprise is carried out by means of a matrix method. The square matrix is taken as a basis of matrix model of estimation of interlevel interaction "results-resources" of economic activity of the enterprises of hospitality (fig. 2). Quantitative indicators that characterize and measure the most important aspects of economic activity of hospitality enterprises are taken as the initial data for the calculation of the elements of the matrix.
In the matrix model, all the original data used have a double interpretation: on the one hand, they characterize the results of economic activity (located above the graphs of the matrix in the first line), on the other hand, they are internal factors influencing the formation of these results (located in the left column of the matrix). Hence the main feature of the matrix method: by identifying different ratios of quantitative indicators of results and internal factors of influence, it is possible to get the relationship of the original indicators. All the obtained ratios (elements of the matrix) are qualitative indicators of the functioning of the enterprise. All elements of the matrix have their own specific economic meaning, from which each name derives. Many of them are already well known, such as: profitability of services, capital efficiency, material equipment and others. But in many cases the name is missing. Then it is possible to use the term "consistency" or a conditional name. For example, "consistency of services provided with the cost of services provided" or cost of services, means the amount of services provided per unit of cost of services provided.

\footnotetext{
Copyright (C) 2021 Author(s), published by Vytautas Magnus University. This is an open access article distributed under the terms of the Creative Commons Attribution Non-Commercial 4.0 (CC BY-NC 4.0) license, which permits unrestricted use, distribution, and reproduction in any medium provided the original author and source are credited. The material cannot be used for commercial purposes.
} 


\begin{tabular}{|c|c|c|c|c|c|c|c|}
\hline Ratio & $\begin{array}{l}\text { Profit } \\
\text { (P) }\end{array}$ & $\begin{array}{l}\text { Services } \\
\text { provided } \\
\quad(\mathrm{SP})\end{array}$ & $\begin{array}{l}\text { Cost of } \\
\text { services } \\
\text { provided } \\
\quad(C S)\end{array}$ & $\begin{array}{l}\text { Average annual } \\
\text { cost of fixed } \\
\text { assets } \\
\text { (FA) }\end{array}$ & $\begin{array}{l}\text { Average annual } \\
\text { cost of working } \\
\text { capital } \\
(W C) \\
\end{array}$ & $\begin{array}{l}\text { Remuneration fund } \\
\qquad(R F)\end{array}$ & $\begin{array}{l}\text { Number of } \\
\text { staff } \\
\text { (S) }\end{array}$ \\
\hline $\begin{array}{l}\text { Profit } \\
\text { (P) }\end{array}$ & $P / P \quad 1$ & $S P / P$ & $C S / P$ & FA $/ P$ & $W C / P$ & $R F / P$ & $\mathrm{~S} / P$ \\
\hline $\begin{array}{l}\text { Services provided } \\
\text { (SP) }\end{array}$ & $P / S P$ & $S P / S P 1$ & $C S / S P$ & FA / НП & $W C / S P$ & $R F / S P$ & $\mathrm{~S} / S P$ \\
\hline $\begin{array}{l}\text { Cost of services provided } \\
\text { (CS) }\end{array}$ & $P / C S$ & $S P / C S$ & $C S / C S 1$ & $\mathrm{FA} / C S$ & $W C / C S$ & $R F / C S$ & $\mathrm{~S} / C S$ \\
\hline $\begin{array}{l}\text { Average annual cost of fixed assets } \\
\qquad(\mathrm{FA})\end{array}$ & $P / \mathrm{FA}$ & $S P / \mathrm{FA}$ & $C S / \mathrm{FA}$ & $\mathrm{FA} / \mathrm{FA} 1$ & $W C / \mathrm{FA}$ & $R F / \mathrm{FA}$ & $\mathrm{S} / \mathrm{FA}$ \\
\hline $\begin{array}{c}\text { Average annual cost of working } \\
\text { capital } \\
(W C)\end{array}$ & $P / W C$ & $S P / W C$ & $C S / W C$ & FA / $W C$ & $W C / W C 1$ & $R F / W C$ & $\mathrm{~S} / W C$ \\
\hline $\begin{array}{l}\text { Remuneration fund } \\
\qquad(R F)\end{array}$ & $P / R F$ & $S P / R F$ & $C S / R F$ & $\mathrm{FA} / R F$ & $W C / R F$ & $R F / R F 1$ & $\mathrm{~S} / R F$ \\
\hline $\begin{array}{c}\text { Number of staff } \\
(\mathrm{S})\end{array}$ & $P / \mathrm{S}$ & $S P / \mathrm{S}$ & $C S / \mathrm{S}$ & $\mathrm{FA} / \mathrm{S}$ & $W C / \mathrm{s}$ & $R F / \mathrm{S}$ & $S / S$ \\
\hline
\end{tabular}

Field of ratio of results of economic activity

\begin{tabular}{|l|l|l|} 
profitability & productivity & effectiveness \\
\hline
\end{tabular}

Resource

interaction field

Figure 2. The generalized matrix of the analysis of results of economic activity of the hospitality enterprises*

(Developed by the authors) 
The sequence of initial indicators in the matrix model should be such that those elements of the matrix, the growth of which is considered positive in terms of enterprise goals, would remain below the main diagonal of the matrix. This arrangement of the original data and the correspondence of the elements of the matrix are called the ordering of the matrix, and the corresponding matrix is called ordered.

The proposed matrix model for assessing the effectiveness of management is based on the main indicators of economic activity of the enterprise: profit (loss), service provided, cost of services provided, average annual cost of fixed assets, average annual working capital, remuneration fund, number of staff.

The whole set of matrix evaluation of management results contains 17 matrices that differ from each other in economic content. The dynamics of the elements of the matrix and the absolute values of the dynamics of the elements are calculated by the formula:

$$
I_{p i j}=\frac{p_{i j}^{\prime}}{p_{i j}}
$$

where $p^{{ }_{i j}}$ - effectiveness indicators on the column;

$$
p_{i j} \text { - effectiveness indicators in the }
$$

row.

The use of cognitive advantages inherent in effectiveness matrices involves not only the analysis of individual effectiveness indicators, but also their generalized, synthesizing consideration. For this purpose, complex indicators are determined - indices of end results of economic activity (quadrilateral) and resource use (small triangle) of the hospitality enterprise. The definition of such indices answers the question of what is the maximum level of effectiveness achieved in the study period. Comprehensive effectiveness indicators: the index of final results of economic activity, the index of resource use (express the change in the relative level of economic effectiveness for the study period and is determined by the formulas:

$$
I_{f r}=\frac{2 \sum_{i=1}^{2} \sum_{j=2}^{g} I_{p i j}^{\prime}}{g^{2}-g}
$$

$$
I_{r u}=\frac{2 \sum_{i=3}^{g-1} \sum_{j=4}^{g} I_{p i j}^{\prime}}{g^{2}-g}
$$

where $g-$ the number of covered data output of effectiveness matrices $(g=7)$;

$$
I_{p i j}^{\prime} \text { - elements of } p \text { matrix of }
$$

effectiveness ( $i-$ as a reflection of the factor, $j-$ as a reflection of the result).

The general level of effectiveness of economic activity of hospitality enterprises is expressed through its complex indicator and is calculated by the formula: 
Table 1. Results of calculation of complex indicators of effectiveness and the general level of effectiveness of economic activity of the hospitality enterprises in 2016-2019

(Developed by the authors)

\begin{tabular}{|c|c|c|c|c|c|c|c|c|c|}
\hline \multirow{2}{*}{$\begin{array}{l}\text { Years /indexes } \\
\text { Name of the } \\
\text { enterprise }\end{array}$} & \multicolumn{3}{|c|}{$2017 / 2016$} & \multicolumn{3}{|c|}{$2018 / 2017$} & \multicolumn{3}{|c|}{$2019 / 2018$} \\
\hline & $I_{f r}$ & $I_{r u}$ & $P_{e a}$ & $I_{f r}$ & $I_{r u}$ & $P_{e a}$ & $I_{f r}$ & $I_{r u}$ & $P_{e a}$ \\
\hline "Angerlina" & $-0,3522$ & 0,5470 & 9,74 & 0,3578 & 0,4565 & 40,72 & $-0,1936$ & 0,2790 & 4,28 \\
\hline "Gostiny Dvir" & 0,1683 & 0,8273 & 49,80 & 0,8984 & 1,0264 & 96,24 & 0,9231 & 0,6728 & 79,79 \\
\hline "Greenstone" & 1,0066 & 0,4871 & 74,68 & 0,4088 & 0,4474 & 42,81 & $-0,2240$ & 0,4691 & 12,26 \\
\hline "Muscat" & $-0,1959$ & 0,7156 & 25,98 & 0,1772 & 0,4163 & 29,68 & 0,8449 & 0,6229 & 73,64 \\
\hline "Bordo" & 0,5334 & 0,4554 & 49,44 & 0,6530 & 0,3794 & 51,62 & 0,2672 & 0,4238 & 34,56 \\
\hline "Non-stop" & 0,2964 & 0,4798 & 38,82 & $-0,4619$ & 1,0045 & 27,13 & 0,0299 & 0,5854 & 30,77 \\
\hline
\end{tabular}




$$
P_{e a}=\frac{I_{f r}+I_{r u}}{n} \times 100 \text {, }
$$

where $P_{e a}-$ the general level of the effectiveness of economic activity of the enterprise;

$n$ - the number of comprehensive effectiveness indicators of economic activity of the enterprise.

$I_{f r}, I_{r u}-$ index of final results of economic activity of the enterprise, index of resources use, respectively.

The results of the calculation of effectiveness indices and the overall level of effectiveness of economic activity of hospitality enterprises are given in table. 1.

The optimal value is $100 \%$, as the best result in which the economic activity of the enterprise is effective, all goals and objectives are fully met. Based on the obtained data with the help of cluster analysis, the ranges of effectiveness of economic activity are pointed out, on the basis of which, the appropriate methodological tools are selected for each of the analyzed enterprises to ensure its balance, in which the level of effectiveness is tied to resource levels. The distribution of hospitality enterprises by effectiveness in the distribution matrix for 2016-2019 is made in the Table 2, and the Table 3., for greater clarity.

Table 2. Gradation of effectiveness of economic activity of the enterprises of hospitality (Developed by the authors)

\begin{tabular}{|c|l|}
\hline Range & \multicolumn{1}{c|}{ Analysis of the range } \\
\hline $0 \leq P_{z \partial} \leq 20$ & $\begin{array}{l}\text { Economic activity is not productive, is at a critical level. Goals and objectives have not been } \\
\text { achieved. Urgent corrective action is needed to identify and address the causes of } \\
\text { inconsistencies. It requires a complete rethinking of the enterprise, based on: analysis of } \\
\text { requirements for business results, in-depth analysis of the process of providing services } \\
\text { through indicators of use of basic resources of the enterprise, determining the degree of } \\
\text { influence of key factors on business results. }\end{array}$ \\
\hline $21 \leq P_{2 \partial} \leq 45$ & $\begin{array}{l}\text { Low level of effectiveness, which is close to critical. The results require in-depth analysis. } \\
\text { Urgent management action is required to identify and address the causes of inconsistencies. }\end{array}$ \\
\hline low & $\begin{array}{l}\text { The intermediate level of economic effectiveness. Goals and objectives are partially } \\
\text { achieved. It is necessary to develop corrective actions to identify and eliminate the causes of } \\
\text { inconsistencies, as well as to conduct analysis using analytical methods. }\end{array}$ \\
\hline $66 \leq P_{2 \partial} \leq 65$ & $\begin{array}{l}\text { Quite a high level of effectiveness. Goals and objectives are close to being achieved. } \\
\text { Management measures need to be put in place to prevent inconsistencies and to be analyzed } \\
\text { using analytical methods. }\end{array}$ \\
\hline high & $\begin{array}{l}\text { Economic activity is effective; it is at a high level. The set goals have been achieved. It is } \\
\text { possible to increase the level of effectiveness due to certain management measures. It is } \\
\text { necessary to regularly diagnose the results and their forecasting, as well as to develop } \\
\text { measures to maintain the achieved level and corrective measures to plan the results of } \\
\text { activities. }\end{array}$ \\
\hline$P_{z \partial} \leq 100$
\end{tabular}

Copyright (C) 2021 Author(s), published by Vytautas Magnus University. This is an open access article distributed under the terms of the Creative Commons Attribution Non-Commercial 4.0 (CC BY-NC 4.0) license, which permits unrestricted use, distribution, and reproduction in any medium provided the original author and source are credited. The material cannot be used for commercial purposes. 
Garafonova Olha, Zhosan Hanna, Marhasova Viktoriia, Tkalenko Nataliia, Trukhachova Kateryna

Table 3. Matrix of distribution of hospitality enterprises by the level of economic effectiveness for 2016-2019

(Developed by the authors)

\begin{tabular}{|c|c|c|c|}
\hline \multirow{2}{*}{ Ranges } & \multicolumn{3}{|c|}{ Years } \\
\cline { 2 - 4 } $0 \leq P_{e a} \leq 20$ & $2017 / 2016$ & $2018 / 2017$ & $2019 / 2018$ \\
\hline $21 \leq P_{e a} \leq 45$ & "Angelina" & - & $\begin{array}{c}\text { "Angelina" } \\
\text { "Greenstone" }\end{array}$ \\
\hline $46 \leq P_{e a} \leq 65$ & "Gon-stop" & $\begin{array}{c}\text { "Angelina" } \\
\text { "Greenstone" } \\
\text { "Muscat" } \\
\text { "Non-stop" }\end{array}$ & $\begin{array}{c}\text { "Non-stop" } \\
\text { "Bordo" }\end{array}$ \\
\hline $66 \leq P_{e a} \leq 85$ & "Greenstone" & "Bordo" & "Gostiny Dvir" \\
\hline $86 \leq P_{e a} \leq 100$ & - & - & - \\
\hline
\end{tabular}

\section{Conclusions}

Therefore, according to the results of the matrix analysis of the effectiveness of economic activity and the data given in the Table 2 and the Table 3 it is possible to draw the following conclusions:

1. Hotel "Angelina" for the period $2016 / 2017$ and 2019/2018 in terms of the overall performance of economic activity was at a very low level. Analysis of individual indicators and generalized components of effectiveness gives reason to believe that this is due to a rather irrational use of enterprise resources. The index of end results of economic activity was negative, and the index of resource use is less than one by almost half because the company suffered losses against the background of increasing the cost of services provided, so the effectiveness was underestimated. However, in 2018/2019 it was set at a low level, which means a change in priorities and a more rational and even distribution of available resources. It is necessary to completely rethink the functioning of the enterprise, as well as to analyze the requirements for business results and identify the main factors that reduce the ability to achieve maximum business results.

2. Hotel "Gostiny Dvir" in 2017/2016 the effectiveness is defined as low indices of final results in relation to the indices of resource use (less than one). As the overall level of economic effectiveness is $49.7 \%$, the goals and objectives were partially achieved and the company received an average level of economic effectiveness. In the period $2018 / 2017$, the company received the highest level of effectiveness of all surveyed companies $-96.24 \%$, but this does not indicate that the goals have been fully achieved, but rather the incorrect planning of results of activities, as there was an overuse of resources, which led to an increase in the cost of services and reduce the possibility of their implementation. In the next period of $2019 / 2018$, the company received a high level of effectiveness, goals and objectives were close to being achieved, but the index of resource use was lower than the index of final results, indicating inconsistency in the use of enterprise resources, it requires management measures using analytical methods to prevent occurrence of inconsistencies.

3. The efficiency of economic activity of the hotel "Greenstone" for the studied periods has declined sharply from a high level $-74.6 \%$ in $2017 / 2016$ and low $-42.8 \%$ in $2018 / 2017$ to ineffective economic activity. Effectiveness indicator was $12.2 \%$, which is below the upper limit of the range - the critical level. All this indicates significant distortions in activity 
effectiveness and resource use. It requires a complete rethinking of the enterprise in-depth analysis of the process of providing services and the management process through indicators of the use of basic resources of the enterprise, identification of the main factors that reduce the effectiveness of economic activity.

4. In the economic activity of the hotel "Muscat" there is a significant recovery because during the study periods, effectiveness increased from a low level in 2017/2016 and $2018 / 2017-25.9 \%$ and $29.6 \%$, respectively, to $73.6 \%$ - a high level in 2019/2018. However, the effectiveness is determined in relation to low indices of resource use, which are less than one; there are significant inconsistencies of fixed assets with working capital, number of staff and wages. All this requires the implementation of management measures to prevent inconsistencies and analysis of resource use using analytical methods.

5. Hotel "Bordo" for the period 2017/2016 and 2018/2017 partially achieved the set goals, planned results and had an average level of economic effectiveness. And in the next period of $2019 / 2018$, productivity decreased by one step and was at a low level $34.5 \%$. This situation is caused by the inconsistency of the main results of economic activity with the cost of resources of the enterprise; both indices are also less than one. This situation requires in-depth analysis, it is necessary to take urgent management action to identify and eliminate the causes of inconsistencies.

6. The effectiveness of economic activity of the hotel "Non-stop" for the periods 2017/2016, 2018/2017 and 2019/2018 was at a low level, it is possible to observe the excess of resource costs over the results of activities, i.e., the cost of hospitality services was at a very low level and as a result the company suffered losses. However, in 2019 there is a positive dynamic of cost-effectiveness, but the company continued to incur losses, so the company's management must take urgent measures to prevent the crisis from escalating and leaving the critical level of performance with a complete rethinking of the enterprise. It is necessary to analyze the requirements for business results, in-depth analysis of the service delivery process and management process through indicators of use of the main resources of the enterprise, identification of the main factors influencing the results of economic activity.

\section{References}

Barsov A.A. (1979) The efficiency of social production. Minsk: Science and Technique, $450 \mathrm{p}$.

Vartanov A.S. (1991) Economic diagnostics of the enterprise: organization and methodology. Finance and Statistics. $216 \mathrm{p}$.

Vasilik S.K. (1998) Efficiency of activity of shareholder enterprises. Dis. of Candidate of Economic Sciences: 08.06.01. $138 \mathrm{p}$.

Gavrilova T. V. Assessment of the results of the effectiveness of the enterprise and the implementation of activity. Available at: http://dspace.nuft.edu.ua/jspui/bitstream/123456789/ 5092/3/Estimation\%20of\%20enterprise's\%20activities\%20results\%20and\%20of\%20activity\%20realization.pdf

Gaidamak N.V. (1999) Effectiveness management of agricultural enterprises- Abstract of the dissertation for the degree of Candidate of Economic Sciences. Available at : http://revolution.allbest.ru/management/00320779_0.html.

Gontareva I.V. Problems of the relationship between the effectiveness and efficiency of the enterprise: Available at:http://www.kneu.kiev.ua/data/upload/publication/main/ua/717/32p82pfh.doc

\footnotetext{
Copyright (C) 2021 Author(s), published by Vytautas Magnus University. This is an open access article distributed under the terms of the Creative Commons Attribution Non-Commercial 4.0 (CC BY-NC 4.0) license, which permits unrestricted use, distribution, and reproduction in any medium provided the original author and source are credited. The material cannot be used for commercial purposes.
} 
Darmits R.Z. Vatsyk N.O. (2010) The relationship of effectiveness and economic efficiency in the management system of the enterprise. Scientific Bulletin of NLTU of Ukraine. Edition 20.12. P. 153-161.

Kosyanchuk T.F., Galkina Yu. G. (2009) Productivity of the enterprise and its diagnostics Bulletin of the Khmelnytsky National University. № 3, T. 1. P. 121 - 124.

Mereste U. (1981) Matrix concept of studying economic efficiency. Study of production efficiency. Tallinn: TPI. P.15 37.

Mereste U. (1985) Fundamentals of efficiency field theory (a new approach to the study of production efficiency through full-system research). Proceedings of the Tallinn Polytechnic Institute № 605. Tallinn. P.5-34.

Mescon M. H., Albert M., Hedoury F. (1992) Fundamentals of Management. Translated from English. «Delo». 702 p.

Pokropivny S.F., Kolot V.M. (1998) Entrepreneurship: strategy, organization, efficiency. KNEU, 352 p.

Svetlichnaya Ya. V. (2002) Estimation and maintenance of economic effectiveness of functioning of road-building enterprises. Dis. Cand. econ. Science: 07/08/03. 185p.

Svetlichnaya Ya. V. (1999) Methodology for evaluating the effectiveness of road enterprises. Proceedings of the international scientific conference "Problems of theory and practice of socially-oriented economy". P. 226 - 227.

Tishchenko A.N., Kizim N.A., Dogadailo L.V. (2005) Economic effectiveness of enterprises: a monograph. 168 p.

Frolova L.V., Semerun L.V. Matrix model of diagnostics of efficiency of management of financial results. Available at: http://www.nbuv.gov.ua/portal/soc_gum/Vdnuet/econ/2010_3/Frolova.pdf.

Chernata T.M. (2004) Comprehensive assessment and analysis of production and economic activities of the enterprise: [Author's abstract of the dissertation for the degree of candidate of economic sciences]. Dnipropetrovsk. $18 \mathrm{p}$.

Sheremet A.D., Saifulin R.S. (1996) Methods of financial analysis. INFRA. 176 p.

Evaluation and Aid Effectiveness OECD. No. 6. Glossary of Key Terms in Evaluation and Results Based Management. Available at: http://www.oecd.org.

Yuriy Kyrylov, Viktoriia Hranovska, Hanna Zhosan, Inna Dotsenko (2020) Innovative Development of Agrarian Enterprises of Ukraine in the Context of the Fourth Industrial Revolution. Solid State Technology. Volume: 63 Issue: 6. pp. 1430-1448. http://solidstatetechnology.us/index.php/JSST/article/view/2218

Zhosan H.V., Trukhachova K.W. (2013) Conceptual provisions of social responsibility of the enterprise as a theoretical basis of balanced effectiveness. Bulletin of the National Khmelnytsky University. Scientific journal. Economic sciences. №4. Volume 2. P. 247-254

Lazarenko, Y., Garafonova, O., Grigashkina, S., Verezomska, I. (2019) Towards an integrated approach to improving innovation management system of mining companies E3S Web of Conferences, 105, 04042 - Available at: https://www.e3sconferences.org/articles/e3sconf/abs/2019/31/e3sconf_iims18_04042/e3sconf_iims18_04042.html.

Dmytro Voronets, Irina Verezomska, Oksana Oliinyk (2019) Diversification Strategy and Sustainable Development of Mining Companies in the Eurasian Mining Region. 3S Web of Conferences Volume 134 Available at: https://www.e3s-conferences.org/articles/e3sconf/pdf/2019/60/e3sconf_sdemr18_03012.pdf

Marhasova V., Grigashkina S., Stabilization Factor for Enterprises during the Crisis Period. E3S Web of Conferences. $\begin{array}{ll}\text { Available at: https://www.e3s- } & \end{array}$ conferences.org/articles/e3sconf/abs/2018/16/e3sconf_iims2018_04006/e3sconf_iims2018_04006.html.

Y. Lazarenko, O. Garafonova, V. Marhasova, S. Grigashkina (2019) The Managerial Aspects of Integrating the Sustainable Development Principles into Practices of Mining Companies. E3S Web of Conferences. Les Ulis. Vol. 134, Les Ulis: EDP Sciences (2019) Available at: https://www.e3sconferences.org/articles/e3sconf/pdf/2019/60/e3sconf_sdemr18_03011.pdf.

Petrenko, V., \& Karnaushenko, A. (2017). JOINT ENTERPRISES IN FOREIGN TRADE ACTIVITY OF UKRAINE. Baltic Journal of Economic Studies, 3(5), 203-207. https://doi.org/10.30525/2256-0742/2017-3-5-203-207 